\title{
DESMILITARIZAÇÃO DA POLICIA
}

Lucas de Melo Souza

Universidade do Oeste Paulista - UNOESTE, Curso de Direito, Presidente Prudente/SP. E-mail: lucasmsouza096@gmail.com

\section{RESUMO}

As forças de segurança no Brasil são a Nacional, Polícia Federal, Rodoviária e Ferroviária, e as estaduais Militar, responsável pelo policiamento ostensivo (rondas) e de preservação da ordem (abordagem e encaminhamento para delegacia), e a Civil, que cuida da parte investigativa e judiciária (encaminhamento de inquérito, por exemplo). A Polícia Militar não tem o título por acaso.

Sua raiz é de fato militar, e seu objetivo mais comum, no mundo, é o de funcionar como uma corporação de reserva das Forças Armadas, para atuar no interior do país em situações de guerra ou conflito. Isso implica que a sua formação histórica é diferente dos agentes civis, assim como a sua formação, seus títulos de hierarquia (capitão, tenente, coronel e major), código penal e objetivo.

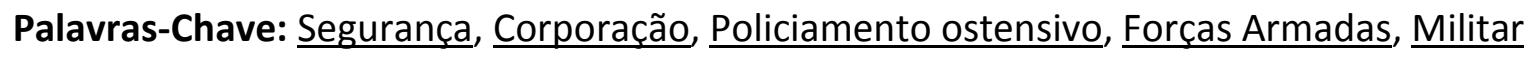




\section{INTRODUÇÃO}

Violência, criminalidade, índices de homicídio alarmantes, narcotráfico, balas perdidas, traficantes, ações policiais. Certamente, tais palavras estão presentes nos assuntos que cotidianamente fazem a pauta dos noticiários nacionais. As pesquisas de opinião para as eleições parlamentares e majoritárias de 2014 demonstram que saúde e segurança pública estão entre os temas que despertam mais interesse para a sociedade brasileira.

Poucos assuntos comovem tanto a opinião pública e aguçam a sangrenta mídia corporativa estabelecida em tamanha intensidade. Os aterrorizantes números demonstram que há uma guerra (ou talvez chacina) em curso. A enorme incidência de crimes violentos, aliada à resposta das autoridades públicas, não é nada satisfatória, envolvendo força excessiva, práticas desumanas, em um círculo vicioso de torturas, maus-tratos e vítimas fatais.

E o cenário não é nada animador. Mais de cinqüenta mil homicídios foram contabilizados em 2013, segundo o Mapa da Violência 20143, formatado com base em estatísticas oficiais dos órgãos nacionais e estaduais de segurança pública.

\section{A PEC 51 E NOVA ARQUITETURA CONSTITUCIONAL}

Com esse contexto explosivo nacional o Senador pelo Estado do Rio de Janeiro Lindbergh Farias, apresentou no Senado Federal a Proposta de Emenda à Constituição (PEC) № 51, de 2013, com a finalidade de reforma da arquitetura institucional da segurança pública ora vigente. Nos dias de hoje, alguns estados experimentaram, ainda que de forma pontual, a redução da criminalidade e queda no número de homicídios. Trata-se, porém, de fenômenos localizados, em locais onde se constata um maior esforço da máquina pública estadual, uma valorização e melhor formação dos policiais, além de maior respeito aos direitos humanos. Tais avanços são sempre condicionados, porém ao texto da Constituição Federal que impede modificações estruturais nos vínculos de força de reserva e engessas as responsabilidades dos entes federativos nos três níveis. A Proposta de Emenda à Constituição no 51/2013 propõe justamente uma modificação constitucional nos dispositivos referentes à segurança pública. Sugere alterar os artigos 21, 24 e 144 da CF e acrescenta os artigos. 143-A, 144- A e 144-B, reestruturando a segurança pública a partir da desmilitarização.

$O$ art. 21, que trata das competências da União, é acrescido dos seguintes incisos

XXVI e XXVII: XXVI - estabelecer princípios e diretrizes para a segurança pública, inclusive quanto à produção de dados criminais e prisionais, à gestão do conhecimento e à formação dos profissionais, e para a criação e o funcionamento, nos órgãos de segurança pública, de mecanismos de participação social e promoção da transparência;

XXVII - apoiar os Estados e municípios na provisão da segurança pública. Já o art. 24, que trata das competências legislativas concorrentes entre União, estados e Distrito Federal é acrescido dos incisos XVI e XVII:

$\mathrm{XVI}$ - organização dos órgãos de segurança pública;

XVII - garantias, direitos e deveres dos servidores da segurança pública. Tais alterações se justificam para destinar mais atividades à União na nova organização de segurança pública, estabelecendo diretrizes nacionais e controle de qualidade na formação dos agentes de segurança. É proposto o art. 143-A objetivando a criação de princípios democráticos e de controle social da atuação dos profissionais de segurança pública, com a seguinte redação:

Art. 143-A. A segurança pública, dever do Estado, direito e responsabilidade de todos, é exercida para a preservação da ordem pública democrática e para a garantia dos direitos dos cidadãos, inclusive a incolumidade das pessoas e do patrimônio, observados os seguintes princípios:

I - atuação isonômica em relação a todos os cidadãos, inclusive quanto à distribuição espacial da provisão de segurança pública; 
II - valorização de estratégias de prevenção do crime e da violência;

III - valorização dos profissionais da segurança pública;

IV - garantia de funcionamento de mecanismos controle social e de promoção da transparência;

V - prevenção e fiscalização efetivas de abusos e ilícitos cometidos por profissionais de segurança pública. Parágrafo único. A fim de prover segurança pública, o Estado deverá organizar polícias, órgãos de natureza civil, cuja função é garantir os direitos dos cidadãos, e que poderão recorrer ao uso comedido da força, segundo a proporcionalidade e a razoabilidade, devendo atuar ostensiva e preventivamente, investigando e realizando a persecução criminal.

$\mathrm{O}$ art. 144 da CF é reestruturado para que a disponha somente sobre a organização da segurança pública no âmbito da União, sendo retirados os incisos IV e V, concernentes hoje as polícias civis e polícias militares e corpos de bombeiros militares. Por fim, são inseridos os artigos 144-A, com a redação abaixo, e o art. 144- B, que prevê o controle externo da atividade policial será exercido, paralelamente ao disposto no art. 129, VII, por meio de Ouvidoria Externa. 35 Art. 144-A. A segurança pública será provida, no âmbito dos Estados e Distrito Federal e dos municípios, por meio de polícias e corpos de bombeiros.

$\S 1$ 을 Todo órgão policial deverá se organizar em ciclo completo, responsabilizando-se cumulativamente pelas tarefas ostensivas, preventivas, investigativas e de persecução criminal. $\S$ 2ำ Todo órgão policial deverá se organizar por carreira única.

$\S$ 3o Os Estados e o Distrito Federal terão autonomia para estruturar seus órgãos de segurança pública, inclusive quanto à definição da responsabilidade do município, observado o disposto nesta Constituição, podendo organizar suas polícias a partir da definição de responsabilidades sobre territórios ou sobre infrações penais.

$\S 4$ ㅇ Conforme o caso, as polícias estaduais, os corpos de bombeiros, as polícias metropolitanas e as polícias regionais subordinam-se aos Governadores dos Estados, do Distrito Federal e dos Territórios; as polícias municipais e as polícias submunicipais subordinam-se ao Prefeito do município.

$\S 5$ 을 Aos corpos de bombeiros, além das atribuições definidas em lei, incumbe a execução de atividades de defesa civil.

Os capítulos anteriores aqui se delineiam para justificar a necessidade de alteração do modelo de segurança pública, no entanto, o atual formato constitucional é inflexível, tornando os avanços nas unidades federativos muito modestos. Como visto, atualmente, a principal força de segurança pública, a Polícia Militar, é organizada de forma militarizada, sendo força de reserva do Exército treinada e formada para o combate ao inimigo, ao invés, de agir como uma polícia cidadã para proteger as pessoas e seu patrimônio. O ciclo da atividade policial é fracionado, ou seja, há uma polícia especializada no policiamento ostensivo e preventivo, a Polícia Militar, e outra responsável pelo investigativo e de persecução criminal, a Polícia Civil.

A existência de bifurcação das carreiras (delegados e não-delegados; oficiais e praças) nas diversas polícias também é causa de disparidades conflituosas internas, ineficiências, progressão funcional limitada.

Da forma como o sistema de segurança pública está hoje estruturado, os entes federativos estaduais concentram a maior parte das obrigações, e a União tem responsabilidade reduzida. Os municípios têm responsabilidade praticamente inexistente, o que vai à contramão das outras demais políticas sociais expressivas, como saúde, educação e previdência social. Um novo perfil para as polícias, condizente com nossos direitos e garantias fundamentais consagrados na Carta Magna, adequado a uma realidade de Estado Democrático de Direito e a uma nova distribuição das responsabilidades federativas, é o objetivo da reforma constitucional pretendida na PEC-51. Neste sentido podemos destacar as seguintes modificações propostas: 
1) Desmilitarização das polícias: reorganizando suas estruturas internas policiais, formação e treinamento. Deseja-se maior autonomia para o policial, acompanhado de maior controle social.

2) Participação da União: fica a cargo da União estabelecer as diretrizes gerais da segurança pública, gestão e compartilhamento de informações e dados, além do fomento de mecanismos para controle social e transparência pública. Adequação nacional de níveis adequados de qualidade, em perspectiva democrática de segurança pública, para a formação policial, cabendo à União avaliar e autorizar o funcionamento das instituições de ensino pertinentes.

3) Definição constitucional de polícia: os corpos policiais passar a ter natureza exclusivamente civil, visando a proteção dos direitos dos cidadãos e da ordem pública democrática. Hoje há um vácuo constitucional na definição da polícia e uma ausência na definição dos princípios fundamentais da segurança pública.

4) Ciclo completo: a necessidade de toda instituição policial abarcar as funções ostensiva e investigativa, pondo fim ao fracionamento da atividade policial. A autonomia das entidades federativas estaduais estará restrita às atribuições por território ou por infração penal específica.

5) Controle externos dos órgãos policiais: a PEC inova ao criar uma Ouvidoria Externa dotada de autonomia funcional, administrativa, dirigida por Ouvidor-Geral independente e com mandato fixo, com competência para regulamentar procedimentos de atuação e disciplinar denúncias e reclamações.

6) Participação dos municípios: as entidades federativas municipais se tornam incluídas de fato no sistema de segurança pública, podendo inclusive, instituir polícias em níveis locais, desde que em decisão tomada pelo estado competente. Observa-se a possibilidade de criação de polícias metropolitanas, havendo a possibilidade de conversão das guardas municipais em polícias municipais, desde que cumpridos todos os requisitos da reforma.

7) Preservação de direitos: a PEC garante todos os direitos de caráter remuneratório e previdenciário dos profissionais de segurança pública, civis ou militares, de modo a satisfazer os desejos da categoria e busca avançar na valorização destes profissionais, inclusive do ponto de vista remuneratório.

8) Carreira única: a proposta determina a carreira única por instituição policial, permitindo ascensão profissional, mediante capacitação e formação, meritocracia, adequando-se as outras carreias do serviço público. Sendo sensível aos diversos contextos estaduais de segurança pública, desafios próprios das entidades federativas e observância ao princípio da autonomia federativa, a PEC propõe que caberá aos estados a decisão sobre formato pelos qual suas polícias operarão: se disporão de atribuições sobre território ou sobre grupos de infração penal ou, ainda, combinando os dois critérios sobre território e sobre grupos de infração penal. Sendo a decisão por território, há a possibilidade de existir uma Polícia Unificada Civil Estadual de toda a população do Estado ou sua divisão em Polícia Metropolitana, Municipal ou Distrital, a cargo das divisões por território de cada estado. Caso seja a escolha por grupo de infração penal pode-se dividir as Polícias em prevenção e investigação de crimes de menor potencial ofensivo, em polícia própria de prevenção e investigação do crime organizado. Se a divisão se der por grupo de infração penal, a polícia ficará autônoma aos Estados. A adoção de uma proposta que abarque tal multiplicidade de formatos policiais ocorre devido à pluralidade de realidades regionais, estaduais e até metropolitanas de nosso país. Imagina-se ainda, na justificativa da PEC, que tal diversidade possa gerar modelos estaduais para as outras entidades federativas. Situação muito diferente do nosso atual contexto, pois hoje o art. 144 da CF engessa todo o modelo policial militarizado vigente no Brasil.

Possui em seu texto prazo de seis anos para adequação ao novo texto constitucional, mas certamente propõe uma ruptura radical com o modelo militarizado, de ciclo incompleto determinante para o fracasso da política criminal e de segurança pública ora em vigor. Aponta na direção de um tratamento mais humano e solidário, democrático e respeitoso, por parte do Estado, aos direitos fundamentais dos cidadãos. Note-se ainda que após anos de duro trabalho a 
Comissão Nacional da Verdade, criada pela Lei 12528/2011 com a finalidade apurar graves violações de Direitos Humanos ocorridas entre 18 de setembro de 1946 e 5 de outubro de 1988, recomenda em seu Relatório Final de dezembro de 2014 a desmilitarização da polícia.

\section{CONCLUSÃO}

O sistema militar policial brasileiro hoje esta fraco, resolve poucos crimes, corrupto, ineficiente, muito burocrático, paga mal (pouco). Este sistema só existe no Brasil, em nenhum outro país. O que ocorre é que este sistema que separa a policia civil e a policia militar onde cada uma delas resolve "pedaços" do policiamento, no qual a policia militar faz o policiamento ostensivo, este que é o policiamento fardado. Ocorre por exemplo um crime, seqüestro, assalto a banco, etc.. A policia militar é chamada para o combate direto. E a policia civil ela faz o policiamento investigativo, que é aquele policiamento no qual ocorre a investigação após o fato, visando em saber quem é o autor do crime, juntar provas, etc... Na maioria dos países mais "desenvolvidos" por assim dizer, a diferenciação destes sistemas não é subdividido, é tudo uma unificação, uma única policia que faz. Pode acontecer, como existe na Europa, por exemplo, a presença da policia militar, mas o método no qual eles trabalham é diferenciado do sistema brasileiro. Em países como Estados unidos, Inglaterra, Austrália, temos o modelo denominado Anglo-Saxão, que é o modelo $100 \%$ civil não existe a policia militar, "militar" para eles é só a força armada. Na Europa Ocidental quem faz o policiamento é a policia civil, nas zonas rurais onde tem a delimitação de fronteiras, utiliza-se a policia militar, porém apenas nos trechos rurais, existem casos específicos também como os batalhões de choque, e combates mais diretos a policia militar nesses casos age. Ainda sim quem faz o policiamento nas zonas urbanas é a policia vil, isso na Europa Ocidental.

Então essa idéia de dividir a função policial é bem antiga, surgindo lá na ditadura militar, onde já existia a divisão das policiais de função militar e civil, porém a policia civil se denominava Guarda Nacional essa policia civil de época ditatorial foi esvaziada nas suas competências e a policia militar foi ampliada, no qual essa era quartelada. E antes da CF de 88 a policia militar tinha muito poder ostensivo, e mesmo com a chegada da constituição de 1988, a policia militar ainda se manteve no seu modelo antigo, modelo esse da ditadura militar, fazendo um alivio cômico, se este modelo atual do Brasil fosse tão bom, deveríamos exportar para o resto do mundo, modelo este que não serve para nenhum país. Outro fato é que o contingente de policiais que trabalhavam na área civil é muito menor do que na policia militar, isso me vem agora na cabeça que muitas pessoas entendem que "desmilitarização" da policia, é fazer com que os policiais andem desarmados, não é nada disso, muito pelo contrário, é a questão de funcionalidade. Depois desse bate-papo introdutório, vou citar alguns pontos que eu acho que são pontos chaves na discussão:

1- O primeiro ponto que acho importante para elencar a "desmilitarização" é a questão de treinamento, como eu já citei é um treinamento mais voltado ao combate, isso é óbvio a idéia de militarismo é inspirado nas forças armadas, o que seria basicamente aniquilar o inimigo externo, entretanto a policia não trabalha com um inimigo externo, e sim com problemas sociais internos.

2 - O militar como já visto historicamente, quando vai para uma guerra, ele logicamente vai pra matar. Óbvio que em situações mais extremas em cenários de troca de tiro e etc. tem que ter o uso da força, porém este não deve ser o foco. Se o sistema tem uma policia violenta, e ela é treinada para ser violenta, não há outro recurso a não ser a violência. Se uma policia é treinado para ser uma policia de neutralização, de negociação de dialogo, ela será treinada dessa maneira, são duas posições diferentes de resoluções de conflito.

3 - Este treinamento militar deve ser feito em situações especificas, porém no Brasil este treinamento é generalizado. O sujeito acabou de entrar na policia, ele é desumanizado com treinamentos, psicológicos, físicos e emocionais, no qual o comandante vai dar ordens e vai 
humilhá-lo, este mesmo sujeito vai querer transferir este sentimento á alguém, descontando na sociedade, o ditado "violência gera violência" é real.

4 - Isso entra na questão do viés pelo qual a policia vai acabar descontando essa violência na população mais pobre. A policia militar é centralizada, disciplina e hierarquia, este sistema é, de novo falando, usado em guerras exteriores pelas forças armadas, onde o superior dá a ordem de combate. A solução que outras policias enfatizam, é tirar esses vigilantes de rua, e colocar em um ambiente mais tranqüilo, investigativo e mais estratégico. No Brasil isso não é possível, pois ou você faz concurso para a policia militar, ou para a policia civil, essa separação de cursos divide também as tarefas e funções, como já abordei, um é investigativo e o outro é ostensivo e não se comunicam, se temos duas estruturas concorrendo entre si, gera uma rivalidade desnecessário pois a policia é um poder estatal e não uma competição sistemática.

5 - Não deveria existir também o tribunal militar, simples motivo, você coloca militar para julgar militar, tende ao fracasso. Há uma primazia de proteção e reconhecimento de oficio ali. A desmilitarização na verdade deve ser feita para tirar este controle centrar da policia militar, claro que não vai resolver tudo, mas é suficiente para reconhecermos uma policia melhor no Brasil.

6 - O nome propriamente dito deveria ser Unificação, é valido pensar em unificar a policia estadual, por exemplo, com um número " $x$ " de habitantes em um determinado território, seria útil. O sistema militar também vem com o que chamo de Ranço, o ranço do nacionalismo, em minha opinião, policial não tem que cantar nacional saldar a bandeira, prestar continência para um colega. São valores que não tornam um profissional melhor do que o outro são meramente ritos propriamente militares, pra que saldar a bandeira? Para justamente combater inimigos! Deixarmos esses valores de nacionalismo, e concentrarmos em uma policia mais competente, fardas, hierarquia, deixar esses fetiches de militarismo e concentrarmos na eficiência.

7 - A policia hoje enxuga gelo, não dá conta de acabar com toda a criminalidade do país em pouco tempo. Gastamos um efeito e contingente em uma droga que toda a pesquisa cientifica indicam que faz melhor do que o álcool! Uma mobilização de recursos públicos jogados no lixo. Gastos com presídios para prender criminosos que a própria policia terá que prender no futuro próximo, um Estado omisso que não dá perspectiva de vida para a população, e uma policia repressiva que atua com a violência. São fatores que tornam nosso sistema tão atrasado.

\section{REFERÊNCIAS}

BATISTA, Nilo. Ainda há tempo de salvar as Forças Armadas da cilada da militarização da segurança pública. Disponível em: http://www.anf.org.br/aindaha-tempo-de-salvar-as-forcas-armadas-dacilada-da-militarizacao-daseguranca-publica/\#.VHi7ejHF-AV

BAYLEY, David H. Padrões de Policiamento: uma análise comparativa internacional. São Paulo: Editora da Universidade de São Paulo. 2006. COMISSÃO NACIONAL DA VERDADE. Relatório Final. Disponível em: http://www.cnv.gov.br/index.php?option=com content\&view=article\&id=571

FÓRUM BRASILEIRO DE SEGURANÇA PÚBLICA. Anuário Brasileiro de Segurança Pública 2014. Disponível em: $\quad$ http://www.forumseguranca.org.br/produtos/anuario-brasileiro-desegurancapublica/8o-anuario-brasileiro-de-seguranca-publica

FÓRUM BRASILEIRO DE SEGURANÇA PÚBLICA. Carta à Nação do Fórum Brasileiro de Segurança Pública. Disponível em http://abordagempolicial.com/2013/07/forum-brasileiro-de-segurancapublicaemite-carta-a-nacao/ 
MENDES, Marcos Baptista. Militarização da segurança pública no Brasil: a polícia militar e os cenários de sua construção histórico-cultural. Disponível em: http://pt.slideshare.net/bengo54/militarizaao-da-seguranapublicanobrasil

MINISTÉRIO DA JUSTIÇA. PRONASCI. Disponível em: http://portal.mi.gov.br/pronasci/data/Pages/MJ3444D074ITEMID2C7FC5BAF0D 5431AA66A136E434AF6BCPTBRNN.htm

DEBATES SOBRE $\quad 0 \quad$ Thttps://youtu.be/ORtUt6wbNhO, https://www.youtube.com/watch?v=cGmYTRIUBL8, https://www.youtube.com/watch?v=Jxhu8ctP3hQ. 